Recepción: 10 / 02 / 2018

Aceptación: 20 / 04 / 2018

Publicación: 15 / 09 / 2018

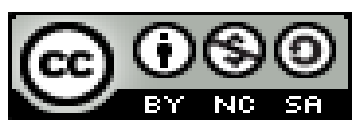

Ciencias económicas y empresariales

Artículo de investigación

\title{
Evaluación estratégica desde una matriz FODA en la empresa aglomerados
}

Strategic evaluation from a SWOT matrix in the agglomerated company Avaliação estratégica de uma matriz SWOT na empresa aglomerada

\author{
Gustavo R. Castillo-Ruano I \\ g.castillo.r@hotmail.com \\ Dayra E. Banguera-Rojas II \\ dayrabanguera@hotmail.com
}

\section{Correspondencia: g.castillo.r@hotmail.com}

I Magister en Administración de Empresas Mención en Negocios Internacionales, Ingeniero Industrial, Docente en la Universidad Técnica de Esmeraldas "Luis Vargas Torres", Esmeraldas, Ecuador.

II Magister en Administración de Empresas Mención en Planeación, Ingeniera Comercial Mención Productividad, Docente en la Universidad Técnica de Esmeraldas "Luis Vargas Torres", Esmeraldas, Ecuador. 


\title{
Resumen
}

En el presente trabajo se da a conocer la evaluación estratégica desde una matriz FODA en la empresa aglomerados. La metodología utilizada fue de tipo descriptiva evaluativa. El corpus de la investigación lo constituyo cada una de las fortalezas, oportunidades, debilidades y amenazas evaluadas en la empresa. El análisis de la información, siguió el método de la hermenéutica, a través de las teorías de la planificación estratégica gerencial. Los resultados permitieron concluir que fundamentado en las fortalezas y las oportunidades de la empresa se debe; capacitar a los empleados para aumentar la eficiencia y aprovechar la tecnología de la empresa. Así como promocionar los productos para captar clientes y aumentar la cuota en el mercado y la gama de productos para tener a disposición de los clientes una línea completa de subministro para el hogar.

Palabras claves: evaluación estratégica; fortalezas; oportunidades; debilidades y amenazas.

\begin{abstract}
In the present work is unveiled strategic assessment from a SWOT matrix Enterprise agglomerate. The methodology used was descriptive and evaluative. The corpus of research created each of the strengths, opportunities, weaknesses and threats evaluated in the company. The analysis of the information, followed the method of hermeneutics, through the theories of management strategic planning. The results allowed to conclude that based on the strengths and opportunities of the company is due; train employees to increase efficiency and take advantage of the company's technology. As well as promote the products to attract customers and increase the market share and product range to have available to customers a complete line of supply for home.
\end{abstract}

Keywords: strategic assessment; strengths; opportunities; weaknesses and threats.

\section{Resumo}

No presente trabalho, a avaliação estratégica de uma matriz SWOT é anunciada na empresa aglomerada. A metodologia utilizada foi de tipo descritivo avaliativo. O corpus da pesquisa foi constituído por cada um dos pontos fortes, oportunidades, fragilidades e ameaças avaliados na 
empresa. A análise das informações seguiu o método da hermenêutica, através das teorias de planejamento estratégico gerencial. Os resultados permitiram concluir que com base nos pontos fortes e oportunidades da empresa é devido; treinar os funcionários para aumentar a eficiência e aproveitar a tecnologia da empresa. Além de promover os produtos para atrair clientes e aumentar a participação de mercado e a gama de produtos para ter uma linha completa de subministração para a casa disponível para os clientes.

Palavras chave: avaliação estratégica; pontos fortes; oportunidades; fraquezas e ameaças.

\section{Introducción}

El análisis Foda es una herramienta de planificación estratégica muy utilizada por las empresas, por su parte, Thompson (1998), indica que la matriz de análisis dafo o foda, es una conocida herramienta estratégica de análisis de la situación de la empresa. El principal objetivo de aplicar la matriz dafo en una organización, es ofrecer un claro diagnóstico para poder tomar las decisiones estratégicas oportunas y mejorar en el futuro. Su nombre deriva del acrónimo formado por las iniciales de los términos: debilidades, amenazas, fortalezas y oportunidades. El análisis interno, revisando las fortalezas y debilidades y un análisis externo, revisando las oportunidades y amenazas de la empresa. Para efectos de estudio se evaluó la matriz FODA a la empresa d aglomerados.

\section{Análisis externo}

El análisis externo se basa, según Porter (1998), en realizar estudios de escenarios de evolución, estudios de evolución de mercados, estudios comparativos de productos de la competencia, etc., con el objetivo de determinar amenazas y oportunidades y valorar la importancia de diferentes ideas innovadoras.

Oportunidades. Son aquellos factores que resultan positivos, favorables, explotables, que se deben descubrir en el entorno en el que actúa la empresa, y que permiten obtener ventajas competitivas. Algunas de las preguntas que se pueden realizar y que contribuyen en el desarrollo son: ¿Qué circunstancias mejoran la situación de la empresa?, ¿Qué tendencias del mercado pueden favorecernos?, ¿Existe una coyuntura en la economía del país?, ¿Qué cambios de tecnología se están presentando en el mercado?, ¿Qué cambios en la normatividad legal y/o 
política se están presentando? Y ¿Qué cambios en los patrones sociales y de estilos de vida se están presentando? (Dale, 1988)

Amenazas. Son aquellos factores que provocan una posición desfavorable frente a la competencia, recursos de los que se carece, habilidades que no se poseen, actividades que no se desarrollan positivamente, etc. También, indica David (1997), son situaciones negativas, externas al programa o proyecto, que pueden atentar contra este, por lo que, llegado al caso, puede ser necesario diseñar una estrategia adecuada para poder sortearlas. Algunas de las preguntas que se pueden realizar y que contribuyen en el desarrollo son: ¿A qué obstáculos se enfrenta la empresa?, ¿Qué están haciendo los competidores?, ¿Se tienen problemas de recursos de capital? y ¿Puede alguna de las amenazas impedir totalmente la actividad de la empresa?

\section{Análisis interno}

Es la exploración de la competencia de una organización, de su posición de costos y viabilidad competitiva en el mercado de la organización. La realización de un análisis interno a menudo incorpora medidas que proporcionan información útil acerca de las fortalezas, debilidades. (Chiavenato (2003).

Fortalezas. Son las capacidades especiales con que cuenta la empresa, y que le permite tener una posición privilegiada frente a la competencia. Por otro lado, el análisis interno de una corporación debe aplicarse diferentes técnicas que permitan identificar dentro de la organización qué atributos le permiten generar una ventaja competitiva sobre el resto de sus competidores. Entre sus fortalezas, se pueden mencionar: locales amplios y cómodos, variedad de productos, atención personalizada con asesoramiento técnico, horarios de atención (de lunes a domingo). Trato al cliente y actitud del equipo de trabajo.

Debilidades. Son aquellos factores que provocan una posición desfavorable frente a la competencia, recursos de los que se carece, habilidades que no se poseen, actividades que no se desarrollan positivamente. También es considerado como todos aquellos elementos, recursos de energía, habilidades y actitudes que la empresa ya tiene y que constituyen barreras para lograr la buena marcha de la organización. También se pueden clasificar: aspectos del servicio que se brinda, aspectos financieros, aspectos de mercado, aspectos organizativos, aspectos de control. Las debilidades son problemas internos que, una vez identificados y desarrollando una adecuada 
estrategia, pueden y deben eliminarse. Algunas de las preguntas que se pueden realizar y que contribuyen en el desarrollo son: ¿Qué se puede evitar?, ¿Qué se debería mejorar?, ¿Qué desventajas hay en la empresa?, ¿Qué percibe la gente del mercado como una debilidad?, ¿Qué factores reducen las ventas? Y ¿Qué haces mal?

\section{Análisis Foda y tomas de decisiones}

La toma de decisiones es un proceso cotidiano mediante el cual se realiza una elección entre diferentes alternativas a los efectos de resolver las más variadas situaciones. En todo momento se deben tomar decisiones. Para realizar una acertada toma de decisiones respecto a un tema, es necesario conocerlo, comprenderlo y analizarlo, para así poder darle solución. Es importante recordar que "sin problema no puede existir una solución". Por ello, las empresas deberían analizar la situación teniendo en cuenta la realidad particular de lo que se está analizando, las posibles alternativas a elegir y las consecuencias futuras de cada elección. Lo significativo y preocupante, es que existe una gran cantidad de empresas que enfrentan sus problemas tomando decisiones de forma automática e irracional (no estratégica), y no tienen en cuenta que el resultado de una mala o buena elección puede tener consecuencias en el éxito o fracaso de la empresa. Las organizaciones deberían realizar un proceso más estructurado que les pueda dar más información y seguridad para la toma de decisiones y así reducir el riesgo de cometer errores. Aquí es donde radica la importancia de la Matriz Foda como elemento necesario para conocer su situación real. Su confección nos permite buscar y analizar, de forma proactiva y sistemática, todas las variables que intervienen en el negocio, con el fin de tener más y mejor información al momento de tomar decisiones.

\section{Metodología}

La metodología utilizada fue de tipo descriptiva evaluativa. De acuerdo a Hernández, Fernández y Baptista (2010), afirman que la investigación descriptiva es la que se orienta a redactar informes relacionados con el estado real de las personas, objeto situaciones o fenómenos tal cual se presentan en el momento de su recolección. En este sentido, el corpus de la investigación lo constituyo cada una de las fortalezas, oportunidades, debilidades y amenazas evaluadas en la empresa. El análisis de la información, siguió el método de la hermenéutica, a través de las teorías de la planificación estratégica gerencial. 


\section{Resultados}

El análisis estratégico de evaluación de la empresa AGLOMERADO se realizó considerando la matriz de análisis dafo o foda, en la cual se obtuvo el siguiente diagnóstico:

Entre sus fortalezas se pudo constatar: variedad de proveedores de herrajes, maquinaria avanzada que agilita el corte de tableros, recurso humano comprometido con su trabajo, eficiencia en entrega de pedidos, bajos costos en tableros de MDP-MDF, servicios adicionales a clientes, importación de tableros desde Colombia y la empresa está ubicada en una vía principal lo que permite que su acceso sea fácil.

Las oportunidades detectadas fueron; aumento de construcción de viviendas, disminución de tala de bosques, demanda insatisfecha, globalización de la tecnología, utilización de las tecnologías para promocionar el producto, mercado en expansión, realizar cursos de asesoramiento para captar clientes y no tiene competidores cerca del lugar donde están ubicados.

Se pudo conocer entre sus debilidades; que no cuentan con Misión ni Visión, inadecuado manejo de inventarios, no cuentan con una estructura organizacional bien definida, falta de un departamento financiero, el área administrativa se encuentra desorganizada, falta de técnicos que supervisen las maquinarias, falta de planificación y dependencia solo de 2 proveedores de tableros.

Por otro lado, se pudieron conocer como amenazas; competencia desleal, aumento de precios en transporte, inestabilidad económica, aumento de precios de productos, productos sustitutos, inestabilidad política, desastres naturales y delincuencia.

\section{Conclusiones}

En aprovechamiento de las fortalezas y las oportunidades de la empresa se debe; capacitar a los empleados para aumentar la eficiencia y aprovechar la tecnología de la empresa. Así como promocionar los productos para captar clientes y aumentar la cuota en el mercado y la gama de productos para tener a disposición de los clientes una línea completa de subministro para el hogar. Finalmente realizar promociones en un monto de compra determinado para favorecer a nuestro cliente y así fidelizarlo. 
Atendiendo las debilidades y oportunidades de la empresa, la misma ha de considerar el establecimiento de su misión y visión para así determinar donde se encuentra y hasta dónde quiere llegar, también obtener una estructura definida y realizar un cronograma de actividades a cumplir e implementar departamentos que agilicen la logística interna en pro de aumentar la clientela.

Frente al uso de sus fortalezas para minimizar sus amenazas, se requiere que promocione los bajos precios en tableros para evitar la incertidumbre en clientes sobre el costo excesivo de productos. Aprovechar el recurso humano para innovar e incluir nuevos modelos de muebles en MDP en el mercado. Asimismo, lograr la contratación de una guardia de seguridad, para disminuir la amenaza que puedan ser asaltados ya que están ubicados en una vía principal. Por otro lado, se requiere que coticen precios a diferentes proveedores para que no les tome por sorpresa la subida de precio de la materia prima.

Para minimizar las debilidades atendiendo las amenazas que enfrenta la empresa, se requiere realizar pedidos en base a las estadísticas de demandas para evitar la falta de productos de alta rotación o el exceso de mercaderías de poca acogida en el mercado; establecer una estructura organizacional que le permita no solo mantenerse en el mercado sino también para ganar terreno en el mismo; contratar técnicos especializados que revisen y les den mantenimiento a la maquinaria y así estar a la par con la competencia y lograr la creación e implantación de la misión y visión para saber la dirección y posición en la que se encuentra.

\section{Referencias Bibliográficas}

Chiavenato (2003). Cómo realizar el Análisis FODA de una empresa. Recuperado en: https://www.rankia.cl > Blogs > Análisis del IPSA

Dale, M (1988) Planning in a Changing Environment, Business Horizons 31, No.5

David, F. (2007), Conceptos de Administración Estratégica, Editorial Prentice Hall Hispanoamericana, S.A., Quinta Edición, 353pp.

Porter, M. (1998), Técnicas para el Análisis de los Sectores Industriales y de la Competencia, Editorial CECSA, México, Vigésima quinta reimpresión, 407pp.

Thompson, B. (1998), Dirección y Administración Estratégicas, Conceptos, casos y lecturas. Edición especial en español. México. Mac Graw Hill Inter americana y editores. 